Original Research Article

\title{
Prescribing patterns of tramadol in hemodialysis patients
}

\author{
Manem Saritha ${ }^{1}$, Pathapati Rama Mohan ${ }^{2} *$
}

${ }^{1}$ Department of Pharmacology, East Point College of Medical Sciences and Research Centre, Bengaluru, Karnataka, India ${ }^{2}$ Department of Pharmacology, Narayana Medical College, Nellore, Andhra Pradesh, India

Received: 06 September 2019

Revised: 22 September 2019

Accepted: 23 September 2019

*Correspondence to:

Dr. P. Rama Mohan,

Email: pill4ill@yahoo.co.in

Copyright: (C) the author(s), publisher and licensee Medip Academy. This is an openaccess article distributed under the terms of the Creative Commons Attribution NonCommercial License, which permits unrestricted noncommercial use, distribution, and reproduction in any medium, provided the original work is properly cited.

\begin{abstract}
Background: Pain is the most common complaint in hemodialysis patients. Tramadol had become analgesic of choice in these patients, and its prescription is increasing day by day. With this background, we evaluated the prescribing trends of tramadol in patients undergoing maintenance hemodialysis.

Methods: A total of 70 prescriptions were audited to assess the prescribing trends of tramadol (usually prescribed as a combination of $37.5 \mathrm{mg}$ tramadol and $325 \mathrm{mg}$ of paracetamol two times a day). Included prescriptions were from both male and female patients above 18 years of age undergoing maintenance hemodialysis. Demographic, clinical and medication use were recorded from the patients.

Results: The mean age of patients was $48 \pm 11.7$ years, duration of dialysis $2.2 \pm 1.4$ years. Tramadol consumptions were observed in $40 / 70(56 \%)$ of patients. Majority of tramadol consumption was found in 30/40 (75\%) males, $23 / 40(59 \%)$ between $40-59$ years and 28/40 (70\%) undergoing two dialyses per week and 13/40 (32.5) were diabetics. During our exploratory analysis, we found that $15 / 40(38 \%)$ of tramadol users, were concurrently prescribed with clonidine as add on antihypertensive. We noticed that the tramadol pill count during the preceding week was 81 in patients concurrently using clonidine and 139 in the patients who were not using clonidine $(\mathrm{p}>0.05)$.

Conclusions: In our study, tramadol consumptions were observed in $56 \%$ of patients. We also noticed analgesic interaction between clonidine and tramadol.
\end{abstract}

Keywords: Clonidine, Interaction, Potentiation, Analgesic, Hemodialysis, Tramadol

\section{INTRODUCTION}

Pain is common among patients on dialysis. Among dialysis patients, the prevalence of pain ranges from $8-$ $82 \% .^{1}$ The high prevalence of pain in the dialysis patients has been linked to depression, and diminished quality of life and poor QOL scores were associated with increased hospitalisation and death. ${ }^{2-4}$ The sources of pain arise predominantly $(62 \%)$ from the musculoskeletal system, followed by other organ systems. ${ }^{5}$
Under treatment of pain in patients on hemodialysis (HD) might be due to analgesic-induced renal-related complications and other drug-accumulation-related complications due to reduced renal clearance., ${ }^{6,7}$ Nonsteroidal anti-inflammatory drugs in dialysis patients because of well-known gastrointestinal, renal toxicities and hypertensive effect. ${ }^{8}$

Paracetamol, a non-narcotic analgesic and tramadol, a centrally acting narcotic analgesic are generally preferred for moderate pain in CKD patients. Paracetamol, at low 
doses, is least nephrotoxic and tramadol is notnephrotoxic.

Additionally, tramadol appears to produce less constipation and dependence than equianalgesic doses of potent opioids. Combination of paracetamol and tramadol has become analgesic of choice to nephrologists.

With this background, we evaluated the prescribing trends of a combination of tramadol and paracetamol in patients undergoing maintenance hemodialysis.

\section{METHODS}

This retrospective data review study was conducted at Narayana Medical College Nellore, during January 2019 to June 2019. Institutional ethics committee approved the study proposal. A total of 70 prescriptions were audited to assess the prescribing trends of tramadol (usually prescribed as a combination of $37.5 \mathrm{mg}$ tramadol and 325 mg of paracetamol two times a day). Included prescriptions were from both male and female patients above 18 years of age undergoing maintenance hemodialysis. Demographic, clinical and medication use were recorded from the patients.

\section{Statistical analysis}

Data was recorded in predesigned case record forms. Results were tabulated as mean and standard deviation for continuous variables and actual numbers and percentages for categorical variables. Chi-square test was an inferential test for categorical variables. A $p$ value of less than 0.05 was considered statistically significant. The data was analyzed by using statistical software IBM SPSS Statistics for Windows, Version 24.0. Armonk, NY: IBM Corp.

\section{RESULTS}

The mean age of patients was $48 \pm 11.7$ years, duration of dialysis $2.2 \pm 1.4$ years. Demographic, clinical and tramadol use can be observed from Table 1 and 2 . Tramadol consumptions were observed in 40/70 (56\%) of patients. Majority of Tramadol consumption was found in $30 / 40(75 \%)$ males, $23 / 40(59 \%)$ between $40-59$ years and $28 / 40(70 \%)$ undergoing two dialyses per week and 13/40 (32.5) were diabetics.

Table 1: Age and gender distribution of tramadol consumers among hemodialysis patients.

\begin{tabular}{|lllllll|}
\hline & Female & \multicolumn{3}{c}{ Male } & Total & \% \\
\hline Age (years) & $\mathbf{N}$ & $\mathbf{\%}$ & $\mathbf{N}$ & $\mathbf{\%}$ & $\mathbf{N}$ & P value \\
& $(15 / 40)$ & $(25.0)$ & $(30 / 40)$ & $(75.0)$ & $(40 / 70)$ & $(57)$ \\
\hline $\mathbf{2 0 - 3 9}$ & 2 & 20 & 6 & 20 & 8 & 20 \\
\hline $\mathbf{4 0 - 5 9}$ & 6 & 60 & 17 & 57 & 23 & 59 \\
\hline $\mathbf{6 0 - 7 9}$ & 2 & 20 & 7 & 23 & 9 & 21 \\
\hline
\end{tabular}

Table 2: The pattern of tramadol prescription across frequency of dialysis.

\begin{tabular}{|c|c|c|c|}
\hline Tramadol prescription & $\mathbf{N}$ & $\%$ & P value \\
\hline Two dialysis/week & $28 / 40$ & 70.0 & \multirow{2}{*}{$>0.05$} \\
\hline Three dialysis/week & $12 / 40$ & 30.0 & \\
\hline
\end{tabular}

Table 3: Tramadol consumption in hemodialysis patients concomitantly with antihypertensive medications.

\begin{tabular}{|c|c|c|}
\hline Tramadol consumption with antihypertensive medications & $\mathbf{N}$ & $\%$ \\
\hline Tramadol + Acetaminophen* & 40 & 57 \\
\hline \multicolumn{3}{|l|}{ Anti HTN drugs } \\
\hline One drug & 7 & 18 \\
\hline Two drugs & 23 & 58 \\
\hline$>/=$ Three drugs & 10 & 26 \\
\hline Clonidine & 15 & 38 \\
\hline Calcium channel blockers & 28 & 70 \\
\hline Beta-blockers & 30 & 75 \\
\hline Angiotensin-converting enzyme inhibitors & 3 & 8 \\
\hline Angiotensin receptor blockers & 1 & 3 \\
\hline Diuretics & 4 & 10 \\
\hline Reserpine & 3 & 8 \\
\hline
\end{tabular}

*40 out of 70 . 
During our exploratory analysis, we found that $15 / 40$ $(38 \%)$ of tramadol users, were concurrently prescribed with clonidine as add on antihypertensive (Table 3 ). We also found that the tramadol pill count during the preceding week was 81 in patients' concurrently using clonidine and 139 in the patients who were not prescribed clonidine. This difference appears to be apparent and is not statistically significant ( $p>0.05)$ (Table 4).

Table 4: Total number of tramadol pills consumed by the hemodialysis patients receiving concurrent clonidine as add no antihypertensive drug.

\begin{tabular}{|c|c|c|c|c|c|}
\hline Pill count & \multicolumn{2}{|c|}{ No clonidine } & \multicolumn{2}{|c|}{ Clonidine } & \multirow{2}{*}{$\begin{array}{l}P \\
\text { value }\end{array}$} \\
\hline $\mathbf{N}$ & $\mathbf{N}$ & $\%$ & $\mathbf{N}$ & $\%$ & \\
\hline 4 & 3 & 7 & 2 & 8 & \multirow{4}{*}{$>0.05$} \\
\hline 5 & 10 & 22 & 8 & 32 & \\
\hline 6 & 7 & 16 & 2 & 8 & \\
\hline 7 & 5 & 11 & 3 & 12 & \\
\hline Total & \multicolumn{2}{|c|}{139 per last week } & \multicolumn{2}{|c|}{81 per last week } & \\
\hline
\end{tabular}

\section{DISCUSSION}

Pain is one of the common problem in patients with endstage renal disease (ESRD). ${ }^{9}$ Managing pain in these patients is always challenging. Tramadol has dual action of pain relief, removed by dialysis, directly nonnephrotoxic and having less abuse potential. ${ }^{10,11}$ Thus, immediate-release tramadol would be the choice of analgesia for hemodialysis patients with mild to moderate pain. $^{12}$

In our study, we found that the Tramadol consumptions were in $40 / 70(56 \%)$ of patients. It was prescribed in combination with paracetamol as a fixed-dose combination in the strength of $37.5 \mathrm{mg}$ tramadol/ $325 \mathrm{mg}$ paracetamol. During our exploratory analysis, we found that $15 / 40(38 \%)$ of tramadol users, were concurrently prescribed with clonidine. The pain relief mechanisms of tramadol are by acting as a central opiate agonist and by inhibiting CNS reuptake of norepinephrine and serotonin. ${ }^{10}$ The literature says that concurrent clonidine use potentiates the analgesic activity of tramadol by locking sympathetic release through the $\alpha_{2}$-adrenergic system.

To assess this potentiation activity, we counted the number of tramadol pills consumed in the last week and found that the pill count was 81 in patients concurrently using clonidine and 139 in those patients who were not prescribed clonidine. This difference appears to be apparent and is not statistically significant ( $\mathrm{p}>0.05)$.

We also assessed the effect of frequency of hemodialysis on the consumption of tramadol; Literature says that dialysis removes tramadol and redosing may be necessary after a dialysis session, indicating more number of tramadol consumers will be in patients undergoing dialysis three times a week. ${ }^{11}$ We found that the number of patients undergoing two times dialysis was more consumers than those undergoing three times dialysis/week. However, the observed difference was only apparent and not statistically significant $(p>0.05)$. The explanations for such a finding could be possibly multifactorial.

\section{Limitations}

Since our study was conducted at one centre, and with a fewer number of samples, theoretically limiting generalisability. Additionally, the retrospective nature of the study and critical analysis of data could have introduced bias. We did not quantify the pain intensity because of a retrospective study.

\section{CONCLUSION}

In our study, Tramadol consumption was more $(56 \%)$ in patients undergoing hemodialysis. We also noticed analgesic interaction between clonidine and tramadol. Further studies are needed to assess the beneficial and harmful interactions between clonidine and tramadol when used concurrently in hemodialysis patients.

\section{Funding: No funding sources}

Conflict of interest: None declared

Ethical approval: The study was approved by the Institutional Ethics Committee

\section{REFERENCES}

1. Murtagh FE, Addington-Hall J, Higginson IJ. The prevalence of symptoms in end-stage renal disease: a systematic review. Adv Chronic Kidney Dis. 2007;14(1):82-99.

2. Perlman RL, Finkelstein FO, Liu L, Roys E, Kiser M, Eisele G, et al. Quality of life in chronic kidney disease (CKD): a cross-sectional analysis in the Renal Research Institute-CKD study. Am J Kidney Dis. 2005;45(4):658-66.

3. Harris TJ, Nazir R, Khetpal P, Peterson RA, Chava P, Patel SS, et al. Pain, sleep disturbance and survival in hemodialysis patients. Nephrology, dialysis, transplantation: official publication of the European Dialysis and Transplant Association - European Renal Association. 2012;27(2):758-65.

4. DeOreo PB. Hemodialysis patient-assessed functional health status predicts continued survival, hospitalization, and dialysis-attendance compliance. American journal of kidney diseases: the official journal of the National Kidney Foundation. 1997;30(2):204-12.

5. Dewar K HS, Pham PT, et al. Chronic kidney disease and pain. J Am Soc Nephrol. 2006: 226.

6. Claxton RN, Blackhall L, Weisbord SD, Holley JL. Undertreatment of symptoms in patients on maintenance hemodialysis. J Pain Symptom Management. 2010;39(2):211-8. 
7. Barakzoy AS, Moss AH. Efficacy of the world health organization analgesic ladder to treat pain in endstage renal disease. J Am Soc Nephrol. 2006;17(11):3198-203.

8. Pope JE, Anderson JJ, Felson DT. A meta-analysis of the effects of nonsteroidal anti-inflammatory drugs on blood pressure. Arch Int Med. 1993;153(4):47784.

9. Davison SN. Pain in hemodialysis patients: prevalence, cause, severity, and management. Am J Kidney Dis. 2003;42(6):1239-47.

10. Kaye AD. Tramadol, pharmacology, side effects, and serotonin syndrome: a review. Pain Physician. 2015;18:395-400.
11. Izzedine $\mathrm{H}$, Launay-Vacher V, Abbara C, Aymard G, Bassilios N, Deray G. Pharmacokinetics of tramadol in a hemodialysis patient. Nephron. 2002;92(3):7556.

12. Conway B, Fogarty D, Nelson W, Doherty C. Opiate toxicity in patients with renal failure. BMJ. 2006;332(7537):345-6

Cite this article as: Saritha M, Mohan PR. Prescribing patterns of tramadol in hemodialysis patients. Int $\mathbf{J}$ Basic Clin Pharmacol 2019;8:2216-9. 